\title{
Assessment of Regional Water Resource Security: A Case Study from Hebei Province, China
}

\author{
Ke SHI, Yijin BAI, Yiru GUO, Yawei CHENG, Yiying HUA, Xinglong YU*
}

\begin{abstract}
The present severe safety situation of water resources has become one of the main risk factors restricting global economic development and influencing social stability and progress. Relieving the current water safety problem and mitigating the restriction imposed on social sustainable development have become popular topics regarding water resource management. Previous index cases were scrutinized and analysed through a wide-range mathematical statistics method based on the "DynamicPressure-State-Influence-Response" (DPSIR) model framework, and 15 strongly associated evaluation indexes were screened out and selected using the grey clustering method following the preliminary identification of 30 influence factors to determine the acting path between the influence factors of water resource safety and the appropriate scientific judgment method. An evaluation model was constructed by integrating the Entropy Weight Method (EWM) and the Technique for Order Preference by Similarity to an Ideal Solution (TOPSIS). The actually surveyed panel data of Hebei Province, China from 2012 to 2018 as taken for example, the weights and correlation functions of the influence factors were calculated, the feedback relationships between the subsystems of water resource safety were analysed, and the water resource safety levels of the criterion and target layers in this region were obtained. Results show that the water resource safety status in Hebei Province in 2012 - 2018 rises from weakly bearable level in 2017 to bearable level, indicating that Hebei Province has achieved good results in its water resource environmental management in recent years. The conclusions can provide governmental water resource management departments with a theoretical reference for scientifically identifying the regional water resource safety status and formulating management and control measures for water resource crisis.
\end{abstract}

Keywords: public administration; security assessment; sustainable development; water resources security

\section{INTRODUCTION}

Various resource problems have continuously emerged around the world with the increasing global environmental change rate and intensity, and the crisis faced by water resources as important basic and strategic resources is especially severe. At the beginning of the $21 \mathrm{st}$ century, water resource safety was proposed in the Stockholm Seminar for the first time, pointing out that the water resource system is an important part facilitating healthy and stable social development and ensuring a benign ecological cycle [1]. As estimated by the World Health Organization and the United Nations Children's Fund, 60 global cities will face very serious safety problems up to 2020 [2]. According to statistics, the average water resource quantity in China over many years is $2.81 \times 1012 \mathrm{~m}^{3}$, ranking 6th in the world, but the per capita water resource quantity is $2300 \mathrm{~m}^{3}$, accounting for $1 / 4$ of the world per capita level. The water deficit in normal years is approximately $400 \times 108 \mathrm{~m}^{3}$, so China is listed by the United Nations as one of 13 countries with water deficit [3]. Meanwhile, given the vast geographic area of China, the water resource quantity of effective utilization varies greatly in regions and with the seasons so that the contradiction between the supply and demand of water resources is prominent. Especially with the rapid promotion of urbanization and the insufficient objective cognition of some local governmental sectors of the water resource safety status in recent years, all kinds of phenomena have emerged, such as severe groundwater overdraft, partially low repeated utilization factor of water resources, serious waste of water, and water quality pollution, all of which have impacted the sustainable development capability of water resources by a large margin $[4,5]$. Therefore, understanding the action mechanism of factors influencing water resource safety and scientifically analysing and evaluating the water resource supply and demand status are the foundation for realizing the efficient utilization of water resources and collaborative economic development in different regions.

In terms of relevant indexes, the main indexes included in the existing research regarding water resource safety status are consumption-type factors, such as per capita water utilization rate, industrial water utilization rate, and urbanization progress, while little attention has been paid to compensation-type factors, such as urban environmental protection input, ecological supply, and sewage treatment rate $[6,7]$. According to the division principle of the index system, scholars have mainly conducted framework construction for water resource pressure, water resource function, economic level, and ecological regime in the past while ignoring the systematic and feedback effect between indexes at each layer [8]. In addition, the analytic hierarchy model of strong subjectivity is mainly used in index weight analysis from the research method perspective, resulting in the insufficient cognition of some factors [9]. The water resource supply and demand safety status system are a multi-factor coupling complex system in which regional economic status, eco-environmental quality, water quantity, and water quality are under a dynamic change process and the influence mechanisms between factors vary. Therefore, to embody the logic feedback effect between different index layers, under the division framework of factors "Dynamic-Pressure-State-InfluenceResponse" (DPSIR) index factors influencing the regional water resource safety status were screened out from multiple dimensions. The system integrality was fully expressed based on the organizational information of causal relationship and the framework of relevant indexes, the survey data of Hebei Province in China was taken for example, and a scientific evaluation method for the water resource safety status was proposed, thus laying a foundation for governmental sectors to scientifically and effectively formulate sustainable development strategies for water resources. 


\section{STATE OF THE ART}

With regard to the analysis and screening of influence factors of the water resource safety status, most of the existing studies have analysed the correlation between historical data and influence factors and determined action degrees of factors on water resource safety through mathematical statistics methods. Taking Luoyang City in China for example, Dong constructed an evaluation index system of water resource safety based on the pressurestate-response framework, determined the index weights following the analytic hierarchy process and using the entropy weight method, and introduced the water resource indexes from 2006 to 2016 into the set to evaluate the analysis model [10]. To analyse the sustainable status of water resources, Chen and Shi used the pressure-stateresponse model to construct a water safety index system, calculated the index weights through the Analytic Hierarchy Process (AHP), conducted a comprehensive evaluation of the urban water safety status in this city using the water resource safety indexes from 2005 to 2013, and proposed relevant measures for strengthening the water environment and the water resource safety capacity based on the evaluation results [11]. Zhang combined the ecological network analysis method and the input-out model to analyse the water use structure and the interactive control relationship between departments in an urban ecosystem and found that the industries with the greatest influence on the urban water resource state are machinery manufacturing and the food and tobacco processing industry [12]. On the basis of the construction framework with the "Press-State-Response" model as the index system, Yang established the system of 23 water resource ecological safety indexes, determined the index weights using the AHP, used relevant mathematical models to calculate the values of the evaluation indexes, and pointed out that the water resource ecological safety in Jinan City in 2007 was in a "sensitive" state [13]. Gao et al. selected relevant influence factors, such as GDP, national economic structure, cross-basin water diversion, and alternative water resources, used the water resource and macroeconomic data in China from 1997 to 2011 to establish the water resource supply and demand model according to the economics theory of balance between supply and demand, conducted an empirical analysis of and predicted the supply and demand balance problem and safety status of water resources in the next 15 years by combining the new requirements proposed by the economic development trend and planning, and raised relevant policy suggestions for the strategic safety of water resources from the perspective of economics [14].

Much research has been conducted on water resource safety status analysis and evaluation. In general, following the steps of index screening, weight determination, and comprehensive evaluation, the main research methods include the AHP, the fuzzy comprehensive evaluation method, system dynamics, the Back Propagation (BP) neural network, and the SPA model $[15,16]$. For instance, Zhang combined the entropy weight method and the SPA model to conduct a comprehensive analysis and evaluation of the water resource safety status in Chongqing, China from 2000 to 2011 to determine the sources of water resource system pressure and propose countermeasures
[17]. Based on ecological footprint theory and method, Dai et al. constructed the ecological footprint, carrying capacity, and ecological safety evaluation models of water resources; introduced the indexes of ecological surplus and deficit, pressure, and footprint intensity of water resources; and then quantitatively evaluated the water resource ecological safety in Liupanshui City located in the karst region. Their results show that the ecological footprint of water resources in Liupanshui included three parts, namely, the ecological footprints of domestic water, production water, and ecological water utilization, and the quantity of deducted water resource in the ecological environment influences the ecological safety of water resources [18]. Lu et al. used the AHP and the Delphi method to calculate and analyse the index weights and on these bases proposed a Vague set-based similarity measurement model of water resource safety evaluation methods, and their study indicates that among nine water resource safety evaluation indexes, urban social, economic, and environmental pressure are relatively high [19]. To evaluate the long-term safety of water resources under the karst landform environment, Sun used an evaluation method combining grey correlation and the matter-element extension model to analyse the water resource safety level by referencing of the karst landform data in Guizhou, China from 2005 to 2012. The great impact of drought on water safety was highlighted; meanwhile, the influence of the inefficient treatment of surface-source agricultural pollution and sewage on water resource safety intensified year by year due to rapid economic development [20]. Bao et al. constructed a comprehensive evaluation index system of water resources from three aspects, namely, water resource background condition, development and utilization degree, and development and utilization efficiency, and determined the thresholds of the evaluation criteria according to development experience and relevant standard for comparable evaluation results at different spatial-temporal scales. Next, they quantitatively evaluated the spatial and temporal pattern of water resource safety in the Beijing-Tianjin-Hebei city agglomeration in 2000 2014 through the AHP and the multi-objective fuzzy membership function under entropy technical support [21].

To sum up, from the division principle of the index system, predecessors have mainly conducted research under "water resource condition-society-economyecology" or "pressure-state-response" framework construction under which the involved scales are relatively narrow, while the corresponding state factors influence the comprehensive evaluation results with spatial change, thereby failing to express the systematic and feedback effects between indexes at each layer very well. Second, the research methods specific to regional water resource safety evaluation mainly include mathematical statistics, linear regression, computer simulation, and relevant mathematical model analysis, and the complex nonlinear relationships and coupling actions between influence factors in the water resource safety system are difficult to explain very well.

Therefore, to tackle the deficiencies of the existing research, case analysis and questionnaire survey were first combined to extract the influence factors of water resource safety, an evaluation index system for regional water resource safety was constructed by taking the DPSIR 
model as the division principle, and relevant social information was effectively captured to fully present the close relation between environment and economy. Next, the survey data of relevant indexes in Hebei Province, China in 2012 - 2018 were taken for example, the entropy weight method was used to calculate the index weights influencing water resource safety, and the Technique for Order Preference by Similarity to an Ideal Solution (TOPSIS) was adopted to comprehensively evaluate the water resource safety influenced by various factors, helping regulators obtain a clear understanding of the current water resource safety status.

The remainder of this study is arranged as follows. Section 3 expounds the method for extracting the influence factors of the water resource safety status, the index system division principle, and the construction method and steps of the grey correlation analysis and fuzzy comprehensive evaluation models. Taking Hebei Province, China for example, Section 4 presents the evaluation of the water resource status and the results obtained for analysis, verification, and discussion. The final section summarizes this study and presents relevant conclusions.

\section{METHODOLOGY}

\subsection{DPSIR-Based Index Analysis Framework}

The DPSIR model was adopted in this study to scrutinize and analyse relevant indexes influencing the regional water resource safety status. This model can integrate the triggering origin and the existing results to establish the relationship with environmental conditions and realize the expression through a logical chain. In the DPSIR model established in this study, driving factor $(D)$ mainly represents the relationship among the population, society, and economy and characterizes the potential causes of the change in water resource safety status; pressure $(P)$ refers to the influence of driving factor $D$ on the natural environment and is a factor acting directly on the change in water resource safety status; state $(S)$ denotes the water resource safety status under pressure $P$; influence (I) expresses the impact of environmental status $S$ on human health and the socioeconomic structure; and response $(R)$ refers to the positive countermeasure taken by human beings to facilitate the sustainable development of water resources [22].

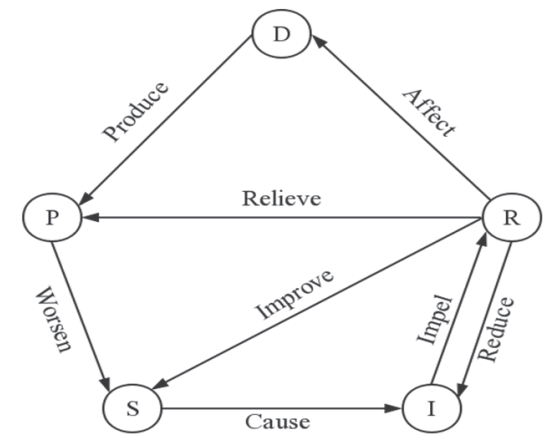

Figure 1 Logical relationship framework in DPSIR model

Including the interaction among the environment, the society, and the economy, the DPSIR model system can realize a comprehensive analysis of a complex system and help governmental management departments, hydrologists, water resource utilization units, and grass roots understand the water resource conditions comprehensively with the organizational information of causal relationship and relevant index framework, and the logical relationship expressed by the model is shown in Fig. 1 .

According to the framework of the DPSIR analysis model and combined with a review of typical cases and the literature, the influence factors of the regional water resource safety status were extracted and screened through questionnaire survey to determine the index factor set.

\subsection{Screening of Evaluation Indexes Based on Grey Clustering}

Scientifically and effectively extracting the factors of the target layer is the foundation for evaluation. If relevant research results are obtained within a large range and the evaluation index system is established according to the frequency statistics method, the data statistics and the computational process will not only be tedious, but some indexes will also repeatedly reflect the same content, resulting in deviation in the evaluation result [23, 24]. Hence, the grey correlation clustering method was employed in this study for quantitative screening in the water supply safety index system, followed by data analysis in strict accordance with the index system structure to ensure the integrity of the index system to the greatest extent. The analysis and calculation steps are as follows:

(1) Standardization of original data.

If $m$ evaluation years and $n$ evaluation indexes are set, then the evaluation index system matrix can be obtained as follows:

$R_{m \times n}=\left[\begin{array}{cccc}x_{1}(1) & x_{1}(2) & \cdots & x_{1}(\mathrm{n}) \\ x_{2}(1) & x_{2}(2) & \cdots & x_{2}(\mathrm{n}) \\ \vdots & \vdots & \ddots & \vdots \\ x_{m}(1) & x_{m}(2) & \cdots & x_{m}(\mathrm{n})\end{array}\right]$

The greater the index values in the index system are, the safer the water supply will be. These indexes are called positive indexes; other indexes present the opposite trend and are thus called negative indexes. For the comparative analysis between different indexes, the linear method was used in this study to standardize indexes into numerical values within $(0,1)$ to eliminate the influence of dimensions between indexes. The nondimensionalized formula is presented as follows:

Standardization of positive indexes:

$b_{i j}=\frac{x_{i j}-\left(x_{j}\right)_{\min }}{\left(x_{j}\right)_{\max }-\left(x_{j}\right)_{\min }}$

Standardization of negative indexes:

$b_{i j}=\frac{\left(x_{j}\right)_{\max }-x_{i j}}{\left(x_{j}\right)_{\max }-\left(x_{j}\right)_{\min }}$

where $b_{i j}$ is the index value $(i=1,2, \ldots, m ; j=1,2, \ldots, n)$ after standardization.

(2) Absolute grey correlation. 
Absolute grey correlation is mainly used to describe the similarity degree of the index sequence curves in a geometric shape, and the more approximate the contours of the sequence curves are, the higher the absolute correlation is. The calculation formula for absolute grey correlation is:

$$
\xi_{i j}=\frac{1+\left|s_{i}\right|+\left|s_{j}\right|}{1+\left|s_{i}\right|+\left|s_{i}-s_{j}\right|}
$$

For a standardized sequence, $X_{i}=\left\{x_{i}(1), x_{i}(2), \ldots, x_{i}(n)\right\}$, the calculation formula of $S_{i}$ is:

$$
S_{i}=\int_{1}^{n}\left(X_{i}-x_{i}(1)\right) \mathrm{d} t
$$

where $\xi_{i j}$ is the absolute grey correlation.

On this basis, the absolute grey correlation $\left(\xi_{i j}(i \leq j)\right)$ between index sequences $X_{i}$ and $X_{j}$ is calculated, and the correlation matrix is constructed as follows:

$$
\left[\begin{array}{cccc}
\xi_{11} & \xi_{12} & \cdots & \xi_{1 m} \\
& \xi_{22} & \cdots & \xi_{2 m} \\
& & \ddots & \vdots \\
& & & \xi_{m m}
\end{array}\right]
$$

For critical value $r \in(0,1), r \geq 0.8$ is generally required. When $\xi_{i j} \geq r(i \neq j), X_{i}$ and $X_{j}$ are considered as evaluation indexes of the same kind. Through grey correlation clustering analysis, the preliminarily determined evaluation indexes are merged so that the indexes can be more independent and the evaluation index system can be simplified.

\subsection{EWM-Based Index Weight Calculation}

In the aspect of concrete weight assignment, the most commonly used at present are the subjective AHP and the objective Entropy Weight Method (EWM). The EWM was derived from the concept of information entropy; entropy is used to measure the uncertainty of random variables in information theory, and information entropy gain is equivalent to information loss, namely, information and entropy are complementary and information is negative EWM [25]. According to the variation degree of each index, information entropy is used to calculate index entropy, and the index weight is then corrected via entropy to obtain the objective index weight. The specific steps are as follows:

$n$ evaluation years and $m$ evaluation indexes are set, and index data matrix $R_{n \times m}$ is established as shown in Eq. (1). $R_{n \times m}=\left(r_{i j}\right)$ is set, where $r_{i j}$ is the $j($ th $)$ index value of the $i$ (th) evaluation object.

Data standardization: The nondimensionalization method is shown in Eq. (2) and Eq. (3).

(1) Data normalization: The formula is shown below:

$$
f_{i j}=\frac{t_{i j}}{\sum_{i=1}^{n} t_{i j}}
$$

\section{$f_{i j} \in(0,1)$ is obtained after normalization.}

(2) The entropy value of index $j$ is calculated as follows:

$$
H_{j}=\frac{\sum_{i=1}^{m} f_{i j} \ln f_{i j}}{\ln m}
$$

(3) Index entropy, namely, the index weight is calculated as follows:

$\omega_{j}=\frac{1-H_{j}}{n-\sum_{i}^{n} H_{j}}$

If $\sum_{j=1}^{n} w_{j}=1$ is satisfied, then the weight vector is obtained as follows:

$\omega_{j}=\frac{1-H_{j}}{n-\sum_{i}^{n} H_{j}}$

\subsection{TOPSIS-Based Evaluation of Water Resource Safety Status}

TOPSIS is a limited-scheme and multi-objective decision analysis method in systems engineering [26]. The basic idea of the method is to define ideal and negative ideal solutions to decision problems and find a solution among the feasible solutions that is closest to the ideal solution and farthest from the negative ideal solution. The specific steps are shown as below:

(1) Index data matrix $R_{m \times n}$ is constructed as shown in Eq. (1).

(2) Data standardization: The nondimensionalization method is shown in Eq. (2) and Eq. (3).

(3) Construction of weighting matrix: Eq. (1) indicates that the weight set determined via the EWM is $W$, and the weighted normalized decision matrix is:

$$
C=\left(c_{i j}\right)_{m \times n}
$$

(4) Determination of positive and negative ideal points: The positive index is:

$$
\begin{aligned}
& C^{+}=\left[\max \left(c_{i j}\right)\right]=\left(C_{1}^{+}, C_{2}^{+}, \ldots, C_{n}^{+}\right) \\
& C^{-}=\left[\min \left(c_{i j}\right)\right]=\left(C_{1}^{-}, C_{2}^{-}, \ldots, C_{n}^{-}\right)
\end{aligned}
$$

The negative index is:

$$
\begin{aligned}
& C^{+}=\left[\min \left(c_{i j}\right)\right]=\left(C_{1}^{+}, C_{2}^{+}, \ldots, C_{n}^{+}\right) \\
& C^{-}=\left[\max \left(c_{i j}\right)\right]=\left(C_{1}^{-}, C_{2}^{-}, \ldots, C_{n}^{-}\right)
\end{aligned}
$$

(5) The distances $\left(S_{i}^{+}\right.$and $\left.S_{i}^{-}\right)$from the sample object to the positive and negative ideal points and the proximity degree are calculated, where the range of proximity degree $E_{i}^{+}$is $(0,1)$. The closer the proximity is to 1 , the closer the sample is to the positive ideal point, and the farther it is from the negative ideal point. Close proximity to the positive ideal point is the best situation, and the opposite is the poorest. 
$S_{i}^{+}=\sqrt{\sum_{j=1}^{n}\left(c_{i j}^{+}-c_{i j}\right)^{2}}, S_{i}^{-}=\sqrt{\sum_{j=1}^{n}\left(c_{i j}^{-}-c_{i j}\right)^{2}}$

$E_{i}^{+}=\frac{S_{i}^{-}}{S_{i}^{+}+S_{i}^{-}}$

\section{RESULTS ANALYSIS AND DISCUSSION}

A case analysis of the regional water resource safety state evaluation was carried out on Hebei Province, China. The feasibility and accuracy of the proposed evaluation model were verified through literature research and the statistical analysis of data from relevant governmental sectors. Hebei Province is one of the provinces of China with severe water resources shortage. The average annual precipitation in this province over many years has been 540 $\mathrm{mm}$, the per capita water resource quantity is approximately $311 \mathrm{~m}^{3}$, and the water resource quantity per mu is approximately $2.08 \mathrm{~m}^{3}$, which barely reaches $1 / 3$ of the internationally recognized per capita water shortage standard of $1000 \mathrm{~m}^{2}$ and is no match to those of the Middle East and North Africa, which are famous for drought and water shortage. Under this background, Beijing and Tianjin divert water (quantity: 1.6 billion $\mathrm{m}^{3}$ ) from reservoirs in Guanting, Miyun, Panjiakou, and Yuqiao every two years on the average, aggravating the contradiction between the supply and demand of water resources in Hebei Province. Therefore, this province must urgently analyze its regional water resource safety status through scientific and effective evaluation methods and formulate relevant powerful measures for solving water resource contradictions, which is an essential precondition for facilitating comprehensive, coordinated, and sustainable regional socioeconomic development and maintaining the sustainable virtuous circle of the environmental system.

\subsection{Preliminary Construction of Water Supply Safety Evaluation Index Set of Hebei Province}

Based on the DPSIR theoretical framework and combined with predecessors methods [27], for extracting the influence factors of the water resource safety status, 152 studies regarding the evaluation of the water resource safety status in 2012 - 2018 were collected and scrutinized in full consideration of the national policies and conditions by referencing the China National Knowledge Infrastructure (CNKI) database; the high-frequency indexes previously used by scholars in water safety evaluation were calculated, followed by the preliminary construction of the regional water resource safety evaluation index set, which contains 30 evaluation indexes (Tab. 1).

Table 1 Water resource safety status index system of Hebei Province, China

\begin{tabular}{|c|c|c|c|c|}
\hline Target layer & Criterion layer & Index layer & Dimensional & Index attribute \\
\hline \multirow{30}{*}{$\begin{array}{l}\text { Water } \\
\text { Resource } \\
\text { Safety } \\
\text { Status } \\
\text { in } \\
\text { Hebei } \\
\text { Province }\end{array}$} & \multirow{4}{*}{$\begin{array}{l}\text { Driving force } \\
\text { factors } \\
A\end{array}$} & GDP growth rate $a_{1}$ & $\%$ & Positive \\
\hline & & Urbanization rate $a_{2}$ & $\%$ & Negative \\
\hline & & Resident disposable income $a_{3}$ & RMB 10000/person & Negative \\
\hline & & Per capita GDP $a_{4}$ & RMB 10000/person & Positive \\
\hline & \multirow{8}{*}{$\begin{array}{c}\text { Pressure factors } \\
B\end{array}$} & Industrial water consumption $b_{1}$ & Billion $\mathrm{m}^{3}$ & Negative \\
\hline & & Agricultural water consumption $b_{2}$ & Billion $\mathrm{m}^{3}$ & Negative \\
\hline & & Residential daily domestic water consumption $b_{3}$ & Billion $\mathrm{m}^{3}$ & Negative \\
\hline & & Effluent discharge $b_{4}$ & Billion $\mathrm{m}^{3}$ & Negative \\
\hline & & Per capita domestic water consumption $b_{5}$ & $\mathrm{~m}^{3}$ & Negative \\
\hline & & Water consumption per RMB 10000 industrial added value $b_{6}$ & $\mathrm{~m}^{3}$ & Negative \\
\hline & & Average irrigation water consumption per mu $b_{7}$ & $\mathrm{~m}^{3}$ & Negative \\
\hline & & Water consumption per RMB 10000 GDP $b_{8}$ & Billion $\mathrm{m}^{3}$ & Negative \\
\hline & \multirow{8}{*}{$\begin{array}{c}\text { State factors } \\
\qquad C\end{array}$} & Per capita water resource quantity $c_{1}$ & Tons/person & Positive \\
\hline & & Annual precipitation $c_{2}$ & $\mathrm{~mm}$ & Positive \\
\hline & & Surface water resources $c_{3}$ & Billion $\mathrm{m}^{3}$ & Positive \\
\hline & & Groundwater resources $c_{4}$ & Billion $\mathrm{m}^{3}$ & Positive \\
\hline & & Water production coefficient $c_{5}$ & $\mathrm{~mm}$ & Positive \\
\hline & & Total water resources $c_{6}$ & $10,000 \mathrm{~m}^{3} /$ day & Positive \\
\hline & & Development utilization rate of water resources $c_{7}$ & $\%$ & Negative \\
\hline & & Large and medium-sized reservoirs $c_{8}$ & Billion $\mathrm{m}^{3}$ & Positive \\
\hline & \multirow{10}{*}{$\begin{array}{c}\text { Ecological } \\
\text { response factors } \\
D\end{array}$} & Urban greening rate $d_{1}$ & $\%$ & Positive \\
\hline & & Forest cover $d_{2}$ & $10000 \mathrm{Mu}$ & Positive \\
\hline & & Drinking water qualification rate in water resource $d_{3}$ & $10000 \mathrm{Mu}$ & Positive \\
\hline & & The rate of good groundwater quality $d_{4}$ & $\%$ & Positive \\
\hline & & The rate of good surface water quality $d_{5}$ & $\%$ & Positive \\
\hline & & The proportion of tertiary industry $d_{6}$ & $\%$ & Positive \\
\hline & & Urban domestic sewage treatment capacity $d_{7}$ & Billion $\mathrm{m}^{3}$ & Positive \\
\hline & & Comprehensive utilization rate of industrial solid waste $d_{8}$ & $\%$ & Positive \\
\hline & & Proportion of investment in water resources and public facilities $d_{9}$ & $\%$ & Positive \\
\hline & & Percentage of the environmental protection investment in GDP $d_{10}$ & $\%$ & Positive \\
\hline
\end{tabular}

\subsection{Selection of Water Resource Safety Evaluation Indexes of Hebei Province \\ 4.2.1 Construction of Grey Correlation Matrix}

This study was based on the analysis of relevant historical data, and the collected index data mainly came from China Statistical Yearbook (2012 - 2018), China Statistical Yearbook on Environment (2012 - 2018), Hebei
Water Resources Bulletin (2012 - 2018), the 13th FiveYear Plan of Hebei Environmental Protection (2012 2018), the 13th Five-year Plan of Hebei Water Conservancy Development, and the statistical information published by some relevant departments, where some data were directly inquired and some were calculated based on the inquired data. The measured data of Hebei Province in 2012 - 2018 were used as the basic data of the evaluation 
indexes and then standardized according to Eq. (2) and Eq.

(3), and Tab. 2 was prepared.

Table 2 Standard values of index data of Hebei Province during 2012-2018

\begin{tabular}{|c|c|c|c|c|c|c|c|c|}
\hline Criterion layer & Index layer & 2012 & 2013 & 2014 & 2015 & 2016 & 2017 & 2018 \\
\hline \multirow{4}{*}{$\begin{array}{l}\text { Driving force } \\
\text { factors } \\
A\end{array}$} & $a_{1}$ & 1.000 & 0.548 & 0.000 & 0.097 & 0.097 & 0.065 & 0.032 \\
\hline & $a_{2}$ & 0.814 & 0.744 & 0.581 & 0.581 & 0.192 & 0.000 & 1.000 \\
\hline & $a_{3}$ & 1.000 & 0.921 & 0.775 & 0.683 & 0.030 & 0.297 & 0.000 \\
\hline & $a_{4}$ & 0.000 & 0.437 & 0.580 & 0.672 & 0.793 & 1.000 & 0.891 \\
\hline \multirow{8}{*}{$\begin{array}{c}\text { Pressure } \\
\text { factors } \\
B\end{array}$} & $b_{1}$ & 0.361 & 0.190 & 0.000 & 0.684 & 0.401 & 1.000 & 0.306 \\
\hline & $b_{2}$ & 0.903 & 0.498 & 0.000 & 0.247 & 0.517 & 0.688 & 1.000 \\
\hline & $b_{3}$ & 0.235 & 0.040 & 0.000 & 0.674 & 0.432 & 0.492 & 1.000 \\
\hline & $b_{4}$ & 0.000 & 0.097 & 0.370 & 0.537 & 0.748 & 0.817 & 1.000 \\
\hline & $b_{5}$ & 0.876 & 0.753 & 0.881 & 1.000 & 0.792 & 0.000 & 0.762 \\
\hline & $b_{6}$ & 0.000 & 0.121 & 0.505 & 0.736 & 0.843 & 0.782 & 1.000 \\
\hline & $b_{7}$ & 1.000 & 0.932 & 0.836 & 0.832 & 0.736 & 0.632 & 0.000 \\
\hline & $b_{8}$ & 0.375 & 0.310 & 0.542 & 0.616 & 1.000 & 0.317 & 0.000 \\
\hline \multirow{8}{*}{$\begin{array}{l}\text { State factors } \\
\qquad C\end{array}$} & $c_{1}$ & 0.000 & 0.673 & 0.732 & 0.743 & 0.703 & 0.862 & 1.000 \\
\hline & $c_{2}$ & 0.000 & 0.938 & 0.846 & 1.000 & 0.650 & 0.359 & 0.732 \\
\hline & $c_{3}$ & 0.250 & 0.263 & 0.000 & 0.174 & 0.831 & 1.000 & 0.472 \\
\hline & $c_{4}$ & 0.174 & 0.370 & 0.000 & 0.007 & 0.642 & 1.000 & 0.361 \\
\hline & $c_{5}$ & 0.000 & 0.286 & 0.429 & 0.714 & 0.857 & 0.571 & 1.000 \\
\hline & $c_{6}$ & 0.090 & 0.000 & 0.179 & 0.203 & 0.679 & 0.454 & 1.000 \\
\hline & $c_{7}$ & 1.000 & 0.869 & 0.739 & 0.641 & 0.510 & 0.036 & 0.000 \\
\hline & $c_{8}$ & 0.000 & 0.537 & 0.738 & 0.716 & 1.000 & 0.837 & 0.832 \\
\hline \multirow{10}{*}{$\begin{array}{l}\text { Ecological } \\
\text { response } \\
\text { factors } \\
D\end{array}$} & $d_{1}$ & 0.632 & 1.000 & 0.732 & 0.528 & 0.000 & 0.683 & 0.817 \\
\hline & $d_{2}$ & 0.175 & 0.000 & 0.592 & 0.696 & 0.682 & 0.447 & 1.000 \\
\hline & $d_{3}$ & 0.000 & 0.142 & 0.209 & 0.058 & 0.430 & 0.645 & 1.000 \\
\hline & $d_{4}$ & 0.000 & 0.308 & 0.587 & 0.711 & 0.443 & 0.922 & 1.000 \\
\hline & $d_{5}$ & 0.000 & 0.276 & 0.558 & 0.346 & 0.608 & 0.409 & 1.000 \\
\hline & $d_{6}$ & 0.000 & 0.137 & 0.438 & 0.595 & 0.713 & 0.885 & 1.000 \\
\hline & $d_{7}$ & 0.000 & 0.195 & 0.282 & 0.428 & 0.664 & 0.953 & 1.000 \\
\hline & $d_{8}$ & 0.000 & 0.212 & 0.344 & 0.459 & 0.698 & 0.919 & 1.000 \\
\hline & $d_{9}$ & 0.000 & 0.337 & 0.620 & 1.000 & 0.433 & 0.254 & 0.513 \\
\hline & $d_{10}$ & 0.000 & 0.362 & 0.774 & 1.000 & 0.835 & 0.357 & 0.638 \\
\hline
\end{tabular}

The standard data in Tab. 3 are substituted into Eq. (4) to calculate the absolute grey correlations between different indexes, and the correlation matrixes of the five subsystem layers are obtained as $A_{\delta}, B_{\delta}, C_{\delta}, E_{\delta}$ and $D_{\delta}$.

$$
A_{\delta}=\left[\begin{array}{cccc}
1.00 & 0.73 & 0.68 & 0.83 \\
& 1.00 & 0.67 & 0.70 \\
& & 1.00 & 0.67 \\
& & & 1.00
\end{array}\right]
$$
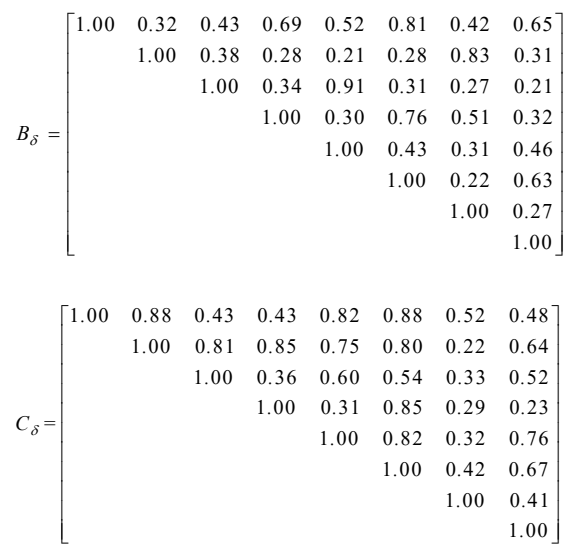

$\left[\begin{array}{llllllllll}1.00 & 0.83 & 0.71 & 0.68 & 0.73 & 0.36 & 0.21 & 0.33 & 0.41 & 0.72\end{array}\right]$ $\left.\begin{array}{llllllllll}1.00 & 0.74 & 0.71 & 0.70 & 0.28 & 0.31 & 0.30 & 0.46 & 0.68\end{array}\right]$ $\begin{array}{llllllll}1.00 & 0.80 & 0.83 & 0.66 & 0.86 & 0.82 & 0.63 & 0.78\end{array}$ $\begin{array}{lllllll}1.00 & 0.76 & 0.53 & 0.62 & 0.71 & 0.62 & 0.82\end{array}$ $\begin{array}{llllll}1.00 & 0.47 & 0.36 & 0.54 & 0.66 & 0.45\end{array}$ $\begin{array}{lllll}1.00 & 0.60 & 0.41 & 0.28 & 0.67\end{array}$ $\begin{array}{llll}1.00 & 0.87 & 0.60 & 0.53\end{array}$ $\begin{array}{lll}1.00 & 0.75 & 0.77\end{array}$ $1.00 \quad 0.92$ 1.00

\subsubsection{Grey Correlation Clustering Analysis}

According to the abovementioned correlation matrixes of the index system, critical value $r$ was taken as 0.8 , a clustering analysis of the five subsystem layers was carried out, and the clustering result table of water supply safety evaluation indexes in Hebei Province was obtained (Tab. $3)$.

Table 3 Clustering of water supply safety evaluation indexes

\begin{tabular}{|c|c|c|}
\hline Target layer & Criterion layer & Clustering results \\
\hline \multirow{4}{*}{$\begin{array}{c}\text { Water resource } \\
\text { safety status in }\end{array}$} & Driving force factors $A$ & $\left(a_{1}, a_{4}\right), a_{2}, a_{3}$ \\
\cline { 2 - 3 } Hebei Province & Pressure factors $B$ & $\begin{array}{c}\left(b_{1}, b_{6}\right),\left(b_{2}, b_{7}\right),\left(b_{3},\right. \\
\left.b_{5}\right), b_{4}, b_{8}\end{array}$ \\
\cline { 2 - 3 } & State factors $C$ & $\begin{array}{c}\left(c_{1}, c_{2}, c_{3}, c_{4}, c_{5}, c_{6}\right), \\
c_{7}, c_{8}\end{array}$ \\
\cline { 2 - 3 } & $\begin{array}{c}\text { Ecological response } \\
\text { factors } D\end{array}$ & $\begin{array}{c}\left(d_{1}, d_{2}\right),\left(d_{3}, d_{4}, d_{5}\right), \\
\left(d_{3}, d_{7}, d_{8}\right),\left(d_{9}, d_{10}\right)\end{array}$ \\
\hline
\end{tabular}

According to the construction rule of the urban water supply safety evaluation index system established in the previous section and by consulting with relevant experts, the clustering results were analyzed as follows:

(1) Per capita GDP $a_{4}$ reflects the production output created by each resident in this region during the study period and more intuitively reflects the regional economic development level. Hence, the index set of the driving force factors is finally determined as $\left\{a_{2}, a_{3}, a_{4}\right\}$.

(2) Industrial water consumption $b_{1}$ and water consumption per RMB 10000 industrial added value $b_{6}$, agricultural water consumption $b_{2}$, average irrigation water consumption per mu $b_{7}$, residential daily domestic water consumption $b_{3}$ and per capita domestic water 
consumption $b_{5}$ all reflect water resource consumption of this region in aspects of industry, agriculture and residents living, so they are of a certain repetition. Given this, the index set of pressure factors is finally established as $\left\{b_{4}, b_{5}\right.$, $\left.b_{6}, b_{7}, b_{8}\right\}$.

(3) Per capita water resource quantity $c_{1}$ intuitively reflects the abundance of water resources in this region during the study period and exhibits great representativeness. Therefore, the index set of state factors is finally constructed as $\left\{c_{1}, c_{7}, c_{8}\right\}$.

(4) Urban greening rate $d_{1}$ representatively reflects the urban environmental quality; drinking water qualification rate in water resource $d_{3}$ can manifest the urban environmental pollution prevention result; and percentage of the environmental protection investment in GDP $d_{10}$ represents the importance degree attached by the city to environmental protection and input level. Hence, the index set of ecological response factors is set as $\left\{d_{1}, d_{3}, d_{6}, d_{10}\right\}$.

\subsubsection{Establishment of Evaluation Index System}

Through the quantitative and qualitative screening of the grey clustering analysis, a water safety evaluation index system with clear hierarchy and independent indexes was finally established, which includes 15 evaluation indexes as shown in Tab. 4.

Table 4 Water supply safety evaluation index system of Hebei Province

\begin{tabular}{|c|c|c|c|c|}
\hline Target layer & Criterion layer & Index layer & Dimensional & Index attribute \\
\hline \multirow{15}{*}{$\begin{array}{l}\text { Water resource } \\
\text { safety status in } \\
\text { Hebei Province }\end{array}$} & \multirow{3}{*}{$\begin{array}{l}\text { Driving force } \\
\text { factors } \\
A\end{array}$} & Urbanization rate $a_{1}$ & $\%$ & Negative \\
\hline & & Resident disposable income $a_{2}$ & $\begin{array}{c}\text { RMB } \\
10000 / \text { person }\end{array}$ & Positive \\
\hline & & Per capita GDP $a_{3}$ & $\begin{array}{c}\text { RMB } \\
10000 / \text { person }\end{array}$ & Positive \\
\hline & \multirow{5}{*}{$\begin{array}{c}\text { Pressure factors } \\
\qquad B\end{array}$} & Effluent discharge $b_{1}$ & Billion $\mathrm{m}^{3}$ & Negative \\
\hline & & Per capita domestic water consumption $b_{2}$ & $\mathrm{~m}^{3}$ & Negative \\
\hline & & Water consumption per RMB 10000 industrial added value $b_{3}$ & $\mathrm{~m}^{3}$ & Negative \\
\hline & & Average irrigation water consumption per mu $b_{4}$ & $\mathrm{~m}^{3}$ & Negative \\
\hline & & Water consumption per RMB 10000 GDP $b_{5}$ & $\mathrm{~m}^{3}$ & Negative \\
\hline & \multirow{3}{*}{$\begin{array}{c}\text { State factors } \\
\qquad C\end{array}$} & Per capita water resources $c_{1}$ & Tons/person & Positive \\
\hline & & Development utilization rate of water resources $c_{2}$ & $\%$ & Negative \\
\hline & & Large and medium-sized reservoirs $c_{3}$ & Billion $\mathrm{m}^{3}$ & Positive \\
\hline & \multirow{4}{*}{$\begin{array}{c}\text { Ecological } \\
\text { response factors } \\
D\end{array}$} & Urban greening rate $d_{1}$ & $\%$ & Positive \\
\hline & & The rate of drinking water quality meeting the standard $d_{2}$ & $\%$ & Positive \\
\hline & & The proportion of tertiary industry $d_{3}$ & $\%$ & Positive \\
\hline & & The proportion of environmental protection investment in GDP $d_{4}$ & $\%$ & Positive \\
\hline
\end{tabular}

\subsection{Weights of Water Resource Safety Evaluation Indexes in Hebei Province}

The indexes in the original evaluation matrix were normalized through Eq. (1), and the index weights under the water supply safety evaluation index system of Hebei Province were calculated according to Eq. (7), Eq. (8), Eq. (9), and Eq. (10), as seen in Tab. 5.

Table 5 Water supply safety evaluation index system of Hebei Province

\begin{tabular}{|c|c|c|c|c|}
\hline Target layer & Criterion layer & Index layer & Index attribute & Weight \\
\hline \multirow{15}{*}{$\begin{array}{l}\text { Water resource } \\
\text { safety status in } \\
\text { Hebei Province }\end{array}$} & \multirow{3}{*}{$\begin{array}{l}\text { Driving force factors } \\
\qquad A\end{array}$} & Urbanization rate $a_{1}$ & Negative & 0.071 \\
\hline & & Resident disposable income $a_{2}$ & Positive & 0.0658 \\
\hline & & Per capita GDP $a_{3}$ & Positive & 0.0738 \\
\hline & \multirow{5}{*}{$\begin{array}{c}\text { Pressure factors } \\
\qquad B\end{array}$} & Effluent discharge $b_{1}$ & Negative & 0.0683 \\
\hline & & Per capita domestic water consumption $b_{2}$ & Negative & 0.0655 \\
\hline & & Water consumption per RMB 10000 industrial added value $b_{3}$ & Negative & 0.0629 \\
\hline & & Average irrigation water consumption per mu $b_{4}$ & Negative & 0.0693 \\
\hline & & Water consumption per RMB 10000 GDP $b_{5}$ & Negative & 0.0596 \\
\hline & \multirow{3}{*}{$\begin{array}{l}\text { State factors } \\
\qquad C\end{array}$} & Per capita water resource quantity $c_{1}$ & Positive & 0.0687 \\
\hline & & Development utilization rate of water resources $c_{2}$ & Negative & 0.0537 \\
\hline & & Large and medium-sized reservoirs $c_{3}$ & Positive & 0.0736 \\
\hline & \multirow{4}{*}{$\begin{array}{c}\text { Ecological response } \\
\text { factors } \\
D\end{array}$} & Urban greening rate $d_{1}$ & Positive & 0.0654 \\
\hline & & Drinking water qualification rate in water resource $d_{2}$ & Positive & 0.0687 \\
\hline & & The proportion of tertiary industry $d_{3}$ & Positive & 0.0683 \\
\hline & & The proportion of environmental protection investment in GDP $d_{4}$ & Positive & 0.0654 \\
\hline
\end{tabular}

\subsection{TOPSIS-Based Calculation of Close Degree of Water Resource Safety Evaluation in Hebei Province}

Based on the previous calculation, the water resource safety evaluation levels $\left(E_{i}\right)$ of Hebei Province in 2012 2018 were calculated through Eq. (12), Eq. (13), Eq. (14), and Eq. (15), and the results are presented in the following table. The water resource bearing levels were divided using the proximity degrees of the four graded critical values for objective and reasonable grade evaluation results of the evaluation objects. Ranges $(0,0.20),(0.20,0.35),(0.35$, $0.65)$, and $(0.65,1)$ represent Grade IV (overload), Grade III (critical), Grade II (weakly bearable), and Grade I (bearable), respectively.

Grade IV (overload) refers to the relationship between supply and demand is in short supply, the contradictions are serious, and the ability to anti-pressure and the ability to recover reduced to the minimum, but if efforts are made, the situation can be slightly improved. Grade III (critical) means that the relationship between supply and demand is 
in short supply, the contradictions are intensified, and the anti-pressure ability and recovery capacity is weak, but effective methods can be used to control and restore it to normal. Grade II (weakly bearable) refers to the excess of supply over demand, but the surplus is not large, and the water resources function is under great pressure, the contradictions have appeared, and recovery capacity is weak. Grade I (bearable) means that the supply exceeds the demand, the surplus is large, and there is no water resources problem, and this situation has a certain antipressure ability and recovery capacity.

The evaluation results of the water resource bearing levels in Hebei Province are presented in Tab. 6.

\begin{tabular}{|c|c|c|c|c|c|c|}
\multicolumn{9}{|c}{ Table 6 Water supply safety evaluation levels Ei of Hebei Province in 2012-2018 } \\
\hline Year & $\begin{array}{c}\text { Driving force } \\
\text { factors }\end{array}$ & Pressure factors & State factors & $\begin{array}{c}\text { Ecological } \\
\text { response factors }\end{array}$ & $\begin{array}{c}\text { Total water resources } \\
\text { bearing capacity }\end{array}$ & $\begin{array}{c}\text { Water resource } \\
\text { evaluation levels }\end{array}$ \\
\hline 2012 & 0.2264 & 0.4217 & 0.3932 & 0.2073 & 0.4328 \\
Weakly bearable \\
\hline 2013 & 0.3036 & 0.4683 & 0.3863 & 0.2715 & 0.4426 & Weakly bearable \\
\hline 2014 & 0.3492 & 0.4896 & 0.3681 & 0.2786 & 0.5017 & Weakly bearable \\
\hline 2015 & 0.3521 & 0.5673 & 0.4528 & 0.3591 & 0.5582 \\
\hline 2016 & 0.3583 & 0.5405 & 0.5093 & 0.4690 & 0.6293 \\
\hline 2017 & 0.3602 & 0.5228 & 0.5372 & 0.5197 & 0.6521 & Weakly bearable \\
\hline 2018 & 0.3677 & 0.5032 & 0.5547 & 0.5088 & Bearable & 0.7029 \\
\hline
\end{tabular}

\subsection{Results Discussion}

The variation tendency chart of the relatively close degrees of driving force, pressure, state, and ecological response factors in $2012-2018$ is shown in Fig. 2.

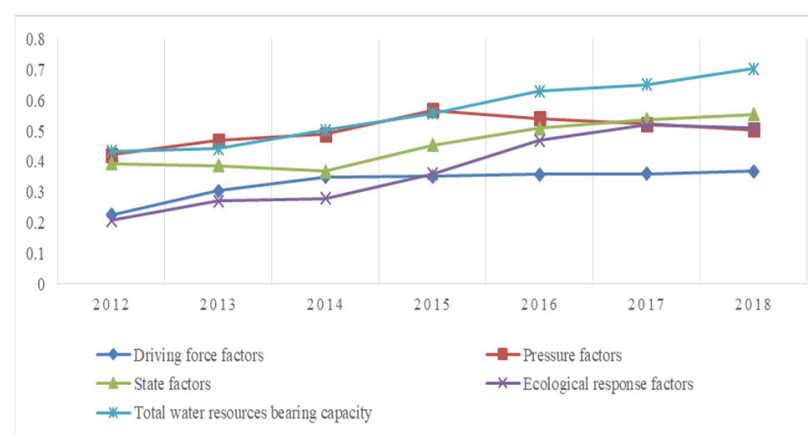

Figure 2 Variation tendency charts of relatively close degrees of water resource safety evaluation subsystems of Hebei Province during 2012 - 2018

(1) The driving force factors were kept in a steady growth phase, but at a low speed, indicating that the socioeconomic construction in Hebei Province in recent seven years achieved certain results, and the urbanization rate, the resident disposable income, and the per capita GDP increased to a certain degree. However, the economic development slowed in recent years. This phenomenon indicates that the socioeconomic structure, which could be borne by water resources in Hebei Province, was still in the initial development phase with a favorable water resource bearing ability and small pressure.

(2) The water resource pressure factors in Hebei Province in 2012 - 2018 were first deteriorated and then optimized. That is, after 2017, Hebei Province positively responded to the green development concept and enjoyed great development in the aspect of water-saving city construction. The water resource environment of Hebei Province improved that considerably by elevating the water resource utilization efficiency, controlling the sewage discharge, and improving the sewage disposal technology.

(3) The variation trend of state factors was basically consistent with that of the pressure sub-factors, namely, the first deterioration and then the optimization trend, indicating that the water-saving awareness of residents and enterprises gradually improved (i.e., no longer in disorderly and blind water resource development state), the reservoir storage capacity elevated step by step, and the water resource environment was gradually optimized with the increasingly enhanced water-saving city construction in Hebei Province in recent years.

(4) The ecological response subsystem of water resource safety evaluation was always in a steady growth phase in Hebei Province din 2012 - 2018, indicating that the industrial structure of Hebei Province was optimized, urban afforestation was strengthened, and the government attached increasing importance to investment on public supporting facilities in the environmental protection field, and the ecological environment of water resources improved to a great extent.

The overall variation trend of the water resource bearing ability in Hebei Province was identical to that of the ecological response factor subsystems, namely, maintaining a steady growth phase, and the water resource evaluation level rose from weakly bearable level in 2017 to bearable level, demonstrating that water resource environmental management in Hebei Province in recent years achieved very good results. Hence, in the future development process of Hebei Province, the influence of ecological environment on its socioeconomic development should still be considered. Overall, development and environmental protection should be considered to realize sustainable development.

\section{CONCLUSIONS}

To tackle regional water resource safety evaluation problem and analysis of its influence factors, the logical feedback relationship between system layers was expounded based on the DPSIR system. The grey clustering model was used to screen 15 indexes among 30 relevant indexes to construct an evaluation system, and then a EWM-TOPSIS based theoretical model for regional water resource safety evaluation was established. The panel survey data of Hebei Province, China in 2012 - 2018 was taken for example, and the water resource safety status in this region was evaluated and analyzed. The following conclusions were finally drawn:

(1) The regional water resource safety state system is an interdisciplinary complex system involving politics, economics, social sciences, and management science. The evaluation system established based on the DPSIR model 
framework can reveal the logical relationship between economic operation and water resource safety status. As the temporal-spatial characteristics of feedback mechanism can be observed between system layers, this evaluation system is of satisfactory feasibility and operability for the comprehensive analysis of the regional water resource safety status.

(2) The grey correlation clustering method was used to perform quantitative clustering analysis on the DPSIR index system to reduce the superposition between indexes, highlight the influences of different links on target layers in regional water resource safety status analysis, and ensure the integrity and high efficiency of the index system.

(3) The EWM-TOPSIS model is relatively feasible when applied to the action mechanism analysis of the influence factors of the regional water resource safety status. By fully considering the relationship between evaluation factors and water resource safety levels, the TOPSIS method can simply and rapidly obtain the evaluation levels through the relative approximation degree. The EWM-TOPSIS model can accurately reflect the safety status of the criterion and target layers with good applicability and high accuracy and provide a new idea for a regional water resource safety evaluation method.

In conclusion, the hierarchical relationship between indexes can be clarified by combining the DPSIR-grey clustering and EWM-TOPSIS models in analyzing and evaluating the influence factors of the water resource safety status. With the importance attached to the effects of influence factors, this study lays a solid research foundation for improving the regional water resource safety status.

\section{REFERENCE}

[1] Farquharson, F., Beran, M., Bromley, J., et al. (2015). Water resources security. Advances in Environmental Research, 3(4), 191-210. https://doi.org/10.1029/95TC03686

[2] Vörösmarty, C. J., Mcintyre, P. B., Gessner, M. O., et al. (2010). Global threats to human water security and river biodiversity.Nature, 467(7315), 555-561. https://doi.org/10.1038/nature09440

[3] Ge, L. Q., Xie, G. D., Li, S. M., et al. (2016). The Analysis of Water Footprint of Production and Water Stress in China. Journal of Resources and Ecology, 7(5), 334-341. https://doi.org/10.5814/j.issn.1674-764×2016.5.003

[4] Bakker, K. (2012). Water security: Research challenges and opportunities. Science, 337(6097), 914-915. https://doi.org/10.1126/science.1226337

[5] Dolmaci, E., Fokaides, P. A., \& Polycarpoua, P. (2018). Energy and environmental assessment of pellets produced from solid residues of the winery industry. Journal of Power Technologies, 98(5), 382-386.

[6] Aksu, U. \& Halicioglu, R. (2018). A eview study on energy harvesting systems for vehicles. TehničkiGlasnik, 12(4), 251-259. https://doi.org/10.31803/tg-20180210153816

[7] Wilk, J. \& Jonsson, A. C. (2013). From water poverty to water prosperity: A more participatoryapproach to studying local water resources management. Water Resources Management, 27(3), 695-713. https://doi.org/10.1007/s11269-012-0209-8

[8] Zhang, A. G., Zhang, X. W., Chen, G. Y., et al. (2018). Ecological security assessment of Luanhe River Basin in Hebei based on PSFR model. Journal of Safety and Environment, (3), 1198-1203.
[9] Draginčić, J. \& Vranešević, M. (2014) AHP-based group decision making approach to supplier selection of irrigation equipment. Water Resources, 41(6), 782-791. https://doi.org/10.1134/S0097807814060050

[10] Dong, G. H., Shen, J. Q., Jia, Y. Z., et al. (2018). Comprehensive evaluation of water resource security: Case study from Luoyang City, China. Water, 10(8), 1106-1125. https://doi.org/10.3390/w10081106

[11] Chen, L. \& Shi, J. (2016). Analysis and predication of urban water security: a case study of Chengdu City, China. Iop Conference, 39(1), 012-027. https://doi.org/10.1088/1755-1315/39/1/012027

[12] Zhang, G., Huang, G. H., Liu, L. R., et al. (2019). Ecological network analysis of an urban water metabolic system based on input-output model: A case study of Guangdong, China. Science of the Total Environment, 670, 369-378. https://doi.org/10.1016/j.scitotenv.2019.03.132

[13] Yang, S. M. \& Xu, Y. T. (2010). Assessing Ecological Security of Water Resource: Methodology and a Case Study of Jinan City in China. 2010 4th International Conference on Bioinformaticsand Biomedical Engineering. https://doi.org/10.1109/ICBBE.2010.5514987

[14] Gao, J., Zhao, N., \& Gao, Q. S. (2014). The model and forecast of water resource supply and demand in China.Statistics \&Decisio, (18), 85-87.

[15] Han, L. W., Liu, M. K., Zhang, H. Y., et al. (2019). Safety assessment model of earth-rock dam based on ideal pointcloud theory. Journal of Engineering Science and Technology Review, 12(4), 38-50. https://doi.org/10.25103/jestr.124.05

[16] Janekova, J., Fabianova, J., \& Fabian, M. (2019). Assessment of economic efficiency and risk of the project using simulation. International Journal of Simulation Modelling, 18(2), 242-253. https://doi.org/10.2507/IJSIMM18(2)467

[17] Zhang, J. Y. \& Wang, L. C. (2015). Assessment of water resource security in Chongqing City of China: What has been done and what remains to be done?Natural Hazards, 75(3), 2751-2772. https://doi.org/10.1007/s11069-014-1460-5

[18] Dai, W., Zhang, M. Z., \& Qin, Q. (2013). Ecological security evaluation of water resource based on ecological footprint model. Environmental Science \& Technology, 36(12), 228233.

[19] Lu, S. B., Bao, H. J., \& Pan, H. L. (2016). Urban water security evaluation based on similarity measure model of Vague-sets. International Journal of Hydrogen Energy, 4l(35), 15944-15950. https://doi.org/10.1016/j.ijhydene.2016.05.007

[20] Sun, D. L., Wu, J. P., Zhang, F. T., et al. (2018). Evaluating water resource security in karst areas using DPSIRM modeling, gray correlation, and matte-element analysis. Sustainability, 10(11), 3934. https://doi.org/10.3390/su10113934

[21] Bao, C. \& Zou, J. J. (2018). Evaluation of water resource security patterns in the Beijing-Tianjin-Hebei urban agglomeration based on human-water relationships. ActaEcologicaSinica, 38(12), 4180-4191. https://doi.org/10.5846/stxb201802260387

[22] Liu, W. X., Sun, C. Z., Zhao, M. J., et al. (2019). Application of a DPSIR modelling framework to assess spatial-temporal differences of water poverty in China. Journal of the American Water Resources Association, 55(1), 259-273. https://doi.org/10.1111/1752-1688.12724

[23] Sangamuang, S. (2019). A graph-based algorithm for interpersonal ties clustering in signed networks. Tehnički Glasnik, 13(4), 275-279. https://doi.org/10.31803/tg-20191104192845

[24] Billenstein, D., Dinkel, C., \& Rieg, F. (2018). Automated topological clustering of design proposals in structural 
optimization. International Journal of Simulation Modelling, 17(4), 657-666. https://doi.org/10.2507/IJSIMM17(4)454

[25] Zhou, R. X., Pan, Z. W., Jin, J. L., et al. (2017). Forewarning model of regional water resources carrying capacity based on combination weights and entropy principles. Entropy, 19(11), 574-588. https://doi.org/10.3390/e19110574

[26] Islam, M. S., Sadiq, R., Rodriguez, M. J., et al. (2013). Evaluating water quality failure potential in water distribution systems: A Fuzzy-TOPSIS-OWA-based methodology. Water Resources Management, 27(7), 21952216. https://doi.org/10.1007/s11269-013-0283-6

[27] Andrade, B. A., Marenco, R. S., Grimaldo, G. J., et al. (2019). Economic assessment of changes in the regulation of the transmission activity in Colombia. Journal of Engineering Science and Technology Review, 12(6), 11-16. https://doi.org/10.25103/jestr.126.02

\section{Contact information:}

Ke SHI, Master degree candidate

School of Politics and Public Administration,

Zhengzhou University, Zhengzhou, Henan, China

E-mail: jsky760@yeah.net

Yijin BAI, Master degree candidate

School of Politics and Public Administration,

Zhengzhou University, Zhengzhou, Henan, China

E-mail: baiyijin123@163.com

\section{Yiru GUO, Master}

School of Management

Wuhan University of Technology, Wuhan, Hubei, China

E-mail: gyrhmh2020@163.com

Yawei CHENG, Master degree candidate

School of Politics and Public Administration,

Zhengzhou University, Zhengzhou, Henan, China

E-mail: cheng27663186@163.com

Yiying HUA, Master degree candidate

School of Politics and Public Administration,

Zhengzhou University, Zhengzhou, Henan, China

E-mail: huayiying789@163.com

\section{Xinglong YU, PhD, Professor}

(Corresponding author)

School of Politics and Public Administration,

Zhengzhou University, Zhengzhou, Henan, China

E-mail: yuxinglong163@163.com 